\title{
Morphological Variations in Buddleia Induced by Gamma Ray Irradiation
}

\author{
Wenhao Dai ${ }^{1,3}$ and Victoria Magnusson ${ }^{2}$ \\ Department of Plant Sciences, North Dakota State University, Department \\ \#7670, P.O. Box 6050, Fargo, ND 58108-6050 \\ Additional index words. butterfly bush, in vitro technique, mutation breeding
}

\begin{abstract}
Buddleia species is commonly used as a perennial for landscaping as a result of its heavy flowers and long bloom period. However, this species has a few concerns such as lack of flower color, excessive growth, and an invasive nature. Attempts to improve Buddleia using conventional breeding methods have resulted in limited success. In this study, mutagenesis by gamma ray irradiation was used to induce genetic variations. In vitro shoot tips of two Buddleia cultivars, B. davidii 'Potters Purple' and Buddleia 'Lochinch', were exposed to 0 to $150 \mathrm{~Gy}$ gamma rays and then recovered in Murashige and Skoog (MS) medium supplemented with $2.5 \mu \mathrm{M}$ benzyladenine (BA). Shoots that recovered from the gamma ray treatment were rooted in half-strength MS medium with $0.5 \mu \mathrm{M}$ naphthalene acetic acid (NAA) and grown in the greenhouse. The growth of shoot tips was inhibited after they were exposed to gamma rays. An average of $50.8 \%$ of shoots treated with 50 Gy gamma rays were recovered, whereas only $9.7 \%$ and $6.5 \%$ of shoots recovered when exposed to 100 and $150 \mathrm{~Gy}$ gamma rays, respectively. After transfer to the greenhouse, a few plants showed reduced growth with some dying before they reached the flowering stage. Various variations including characteristics of leaves (shape, size, hairs), stems (shape, internode length, branching), flowers (color, size, and structure), and plant stature were observed. This research demonstrates that in vitro mutation induction using gamma ray irradiation could be a useful protocol to develop new cultivars or genetic materials for further breeding of Buddleia or other related species.
\end{abstract}

Development of new cultivars is largely dependent on the availability of breeding germplasm and methodology. Breeders are seeking plant materials to breed novel plants; however, their achievement is largely limited as a result of lack of suitable plant materials. In many plant species, the spectrum of existing genetic variations is narrow, which limits production of new and desired gene recombinants through conventional breeding methods. Genetic variations that landscape plant materials possess primarily occur naturally from spontaneous mutations. The frequency of spontaneous mutation is usually very low and a few variations such as flower color, disease resistance, and plant stature have been intensively used in many breeding programs. Therefore, mutation induction technology would provide a significant tool to rapidly create genetic variations for plant improvement (Ahloowalia et al., 2004).

Received for publication 6 Sept. 2011. Accepted for publication 9 Nov. 2011.

This research was supported in part by McIntireStennis Project ND06212 and Landscape Plant Development Center (LPDC).

We are grateful to Dr. J. Schuh for her assistance in irradiation treatment of the plant materials. We thank Drs. E. Deckard, H. Hatterman-Valenti, and R. Smith for reviewing the manuscript.

${ }^{1}$ Associate Professor.

${ }^{2}$ Research Specialist.

${ }^{3}$ To whom reprint requests should be addressed; e-mailwenhao.dai@ndsu.edu.
Mutations, defined as genetic changes at the DNA level (Van Harten, 1998), can occur naturally or be induced by physical or chemical mutagens (Predieri, 2001; Schum, 2003). Mutation breeding has been shown to be an established method to develop new cultivars of many horticultural plants (Mandal et al., 2000; Predieri, 2001; Van Harten, 1998). However, the appearance of chimeras and the perennial nature of many horticultural species make the selection of a stable and homogenous mutant a difficult and long-time process because the mutation often occurs in a small portion of the tissue surrounded by normal tissues (stems, buds, or shoot tips) and isolation of these mutated tissues from a big plant sector can be a challenge (Schum, 2003; Van Harten, 1998).

Advantages of in vitro technology in mutation induction and identification have been determined. Under in vitro conditions, determination of $\mathrm{LD}_{50}(50 \%$ of treated plant materials died) or other parameters is easier; mutation lines can be propagated at a large scale with a relative short time (subcultured once a month and year-round) for a speed establishment of stable periclinal chimeras; plant regeneration from single undifferentiated cell lines may circumvent problems associated with the formation of chimeras; and an in vitro system itself is a source of mutations (somaclonal variations) (Chen and Henny, 2006; Larkin and Scowcroft, 1981). Combining mutation induction and in vitro technology can hasten the breeding process considerably because most of the work can be done under in vitro conditions. Moreover, the in vitro shoot tip is ideal for mutation induction because it contains one or very few meristems, making the selection process simple and efficient (Predieri, 2001).

Application of in vitro techniques for plant improvement has been accomplished in many agronomic and horticultural species (Maluszynski et al., 1995; Predieri, 2001). The mutation varieties database $(<\mathrm{http}: / /$ www-mvd.iaea.org $>$ ) reported that $\approx 2600$ plant varieties derived from physical or chemical mutations had been released worldwide in the past 70 years. Recent advancement of molecular genetics and functional genomics facilitates screening of mutations and speeds up the breeding process and increases efficiency (<http://www-naweb.iaea.org/nafa/ index.html and http://www.fao.org $>$ ).

Buddleia davidii, known as butterfly bush, is commonly used for landscaping. Butterfly bush was imported to North America from China $\approx 1900$ s as a garden shrub. It is a fastgrowing deciduous shrub reaching 1 to $5 \mathrm{~m}$ tall and is often lanky and wide-spreading. Its heavy flowers and long bloom period (from early summer to late fall) are attractive to gardeners. This species is also characterized as winter-hardy and tolerant of a high soil $\mathrm{pH}$ and can be grown in most states of the United States (Dirr, 1998; Hogan, 2003). However, this species has a few concerns such as poor or non-vibrant flower color, excessive growth, and invasiveness (Podaras, 2005). Attempts to improve Buddleia using conventional breeding methods have resulted in limited success because the different ploidy level of species in the genus Buddleia impedes the interspecific crosses (Tobutt, 1993). The objective of this research was to induce desired genetic variations such as dwarf and compact stature and different flower colors of Buddleia species by gamma ray irradiation for cultivar improvement.

\section{Materials and Methods}

Plant material. Two Buddleia cultivars, Buddleia davidii 'Potters Purple' and Buddleia 'Lochinch', were used in this study. Tissue cultures of the two cultivars have been developed and maintained (Dai and Castillo, 2007). In brief, in vitro shoots were subcultured every 4 weeks in MS medium (Murashige and Skoog, 1962) supplemented with $2.5 \mu \mathrm{M}$ BA, $2 \%$ sucrose, and $0.35 \%$ phytagel (Sigma Chemical Co., St. Louis, MO). The medium $\mathrm{pH}$ was adjusted to 5.8 before autoclaving. All cultures were maintained at $25^{\circ} \mathrm{C}$ under coolwhite light $\left(\approx 36.4 \mu \mathrm{mol} \cdot \mathrm{m}^{-2} \cdot \mathrm{s}^{-1}\right)$ with a $16 / 8$-h photoperiod.

Variation induction. In vitro shoot tips were excised from 4-week-old shoots in vitro and placed in a $10 \times 50-\mathrm{mm}$ petri dish sealed with parafilm for gamma ray $\left({ }^{137} \mathrm{Cs}\right)$ treatment at the doses of $0,50,100$, and 150 Gy (gamma ray exposure times were $0,6,12$, and $18 \mathrm{~min}$, respectively) at a facility in the Department of Veterinary and Microbiological Sciences at North Dakota State University. The experiment was conducted as 
a completely randomized design with a $2 \times 4$ factorial arrangement of cultivar and gamma ray dosage with three replications. Each treatment had three plates with $10-15$ shoot tips per plate. After treatment, shoot tips were placed in MS medium with $2.5 \mu \mathrm{M}$ BA for 4 weeks and then subcultured every 4 weeks in the half-strength MS medium with $0.5 \mu \mathrm{M}$ NAA for shoot recovery in the culture room. Recovered (rooted) plants were transferred to a flat filled with Jiffy Mix (Jiffy Mix, Shippagan, Canada) and covered with a clear plastic top for 1 week. The cover was gradually removed during the next 1 -week period. Survival plants were then potted into Sunshine Mix \#1 (Fisons Western Corp., Vancouver, Canada) and grown in the greenhouse. The recovery rate was calculated as the percentage of initial shoot tips producing roots after 12-16 weeks of culture (three to four subcultures). The entire experiment was repeated twice.

Morphological variation screening. Screening of morphological variation started after the recovered plants reached the flowering stage in the greenhouse. Variations were screened plant by plant. Variations in leaves (size, shape, margin, and hair), stems (shape and leaf arrangement), and flowers (color, petal number, inflorescence size, and structure) were recorded. Plant stature was evaluated according to the height, internodal length, and branching. After first screening, plants were cut back to the base to force new shoots to grow. New plants were screened for variations again after their second bloom in 2 to 3 months.

\section{Results}

\section{Effect of gamma ray dosage on in vitro shoot recovery}

All shoot tips were cultured in vitro after being irradiated with the gamma ray. In the first month, more than half of shoot tips irradiated with 100 or 150 Gy gamma ray died and no shoot growth was observed (data not shown). The majority of the shoot tips irradiated with gamma ray at 50 Gy remained green, although some shoot tips did turn brown. In the second month, the remaining shoots appeared to slowly resume growth except those from the 150-Gy treatment. Growth inhibition was also observed in the third month and during the in vitro rooting stage. Rooting of recovered shoots was significantly affected by the irradiation level; the higher the gamma ray dosage re-



Fig. 1. Effect of gamma ray dosage on shoot recovery of two Buddleia cultivars. Vertical bars represent SE. ceived, the lower the rooting rate. An average of $50.8 \%, 9.7 \%$, and $6.5 \%$ of shoots was recovered (rooted) from the treatments of 50, 100 , and 150 Gy, respectively. Difference in shoot recovery was not significant between two cultivars and between the treatments of 100 and 150 Gy (Fig. 1).

\section{Determination of morphological variations}

A total of 1369 shoot tips were irradiated with gamma ray at 50-150 Gy. After three to four subcultures, 304 plants were recovered (rooted). Along with 93 control plants, all 397 plants were transferred to the greenhouse. Some rooted plants, particularly those from the high-dose treatments, appeared to be struggling and eventually died in the greenhouse. A total of 188 plants (114 'Potters Purple' and 74 'Lochinch') survived and reached the flowering stage in the greenhouse in which 37 mutants (23 from 'Potters Purple' and 14 from 'Lochinch') were identified (Table 1). Some variations were still observed after the original plants were cut back and bloomed again. A wide spectrum of variations in leaves, stems, flowers, and plant stature was observed (Fig. 2).

Leaf variations. Original leaves of 'Potters Purple' are opposite, simple, lanceolate with closely serrate or serrulate margins (Fig. $2 \mathrm{~A}$, a). Under the greenhouse condition, the mature leaf was $\approx 11-14 \mathrm{~cm}$ long and $3-4 \mathrm{~cm}$ wide, dark green above, and glabrous silver beneath. Buddleia 'Lochinch' has opposite, simple, ovate-lanceolate, gray-green leaves with white hairs beneath and crenate margins. In the greenhouse, the mature leaf was $\approx 8-11$ $\mathrm{cm}$ long and $3-4.5 \mathrm{~cm}$ wide (Fig. 2A, b). Variations in leaves were seen on the different plants of both cultivars. These variations included narrowed leaves (less than $3 \mathrm{~cm}$ wide) (Fig. 2A, c), deformed leaves (Fig. 2A, $\mathrm{d}-\mathrm{g}$ ), and varied margins (Fig. 2A, h). Leaf hairs were absent in some plants (Fig. 2A, h). Leaf arrangement changed from opposite to alternate or whorled (Fig. 2B, b-c).

Stem variations. The original stem of 'Potters Purple' is round with short hairs. The original stem of 'Lochinch' appears to be square. One significant stem variation that was often seen in 'Potters Purple' plants was a flat stem (Fig. 2B, a). On the flat stem, no clear nodes were seen and leaves grew sporadically with or without lateral buds; however, branches that developed from the flat stem appeared to be normal. Inflorescences that developed from the flat stem were deformed (Fig. 2B, e). Multibranches grew from a single node on some plants (Fig. 2B, d) and formed a round-shaped plant. The internodes on some plants were shortened by $20 \%$ to $50 \%$ (Fig. $2 \mathrm{~B}, \mathrm{f}$ ); however, on other plants, the internodes were largely longer than the original ones.

Flower variations. Flower variations included a change in size and number of inflorescences, flower color, and petal number. Generally, one inflorescence developed from each axillary or apical floral bud in the control plants (Fig. 2C, a). In this study, multiple inflorescences were observed from the apical bud of the main stem (Fig. 2C, b). Some inflorescences developed a stem-like structure on which each node had its own flower cluster (Fig. 2C, c). A top-split inflorescence was also observed (Fig. 2C, d). Flower color varies from purple in the control plants to white or very light pink flowers and the number of petals on each flower varied from four to six in several inflorescences (Fig. 2C, e).

Plant stature. Plant height and texture varied among the mutant plants. As described, changes in branching, the length of internodes, and leaf size resulted in the change of the overall structure of the treated plants. Some plants had a small and compact stature with a fine texture, whereas others were lanky with a coarse structure (Fig. 2D).

\section{Discussion}

Development of novel plant materials through gamma ray irradiation has been accomplished in many horticultural species including pear (Predieri et al., 1997), chrysanthemum (Datta et al., 2001), and turfgrass (Li et al., 2010). Variations in many important horticultural traits such as flower color, flower size, plant shape, and height have been effectively induced and identified (<http://www-mvd.iaea.org $>$ ).

Plant tissue culture technology can largely increase the efficiency of mutation induction and selection, particularly for plants that can be micropropagated because frequent subculturing of treated plant materials (once a month) will speed up the process of selecting homogeneous mutants and produce a large quantity of clones for further evaluation (Maluszynski et al., 1995; Predieri, 2001). In this study, two Buddleia cultivars with colorful and fragrant flowers, but excessive growth, were used. The tissue culture system of these two cultivars has been developed. Shoot tips collected from in vitro plants were exposed to gamma ray irradiation and recovered in vitro. After transferring to the greenhouse, some plants did not grow normally and died before they reached the flowering stage. Tolerance of the two cultivars to gamma ray irradiation varied. More plants of 'Potters Purple' than 'Lochinch' survived from the 50-Gy treatment; however, more plants of 'Lochinch' than 'Potters Purple' survived from the 100-Gy treatment. No plants recovered from the 150-Gy treatment survived

Table 1. Variations induced by gamma ray irradiation in two Buddleia cultivars.

\begin{tabular}{lccccc}
\hline Cultivar & $\begin{array}{c}\text { No. of shoot } \\
\text { tips irradiated }\end{array}$ & $\begin{array}{c}\text { No. of shoots } \\
\text { recovered }\end{array}$ & $\begin{array}{c}\text { No. of shoots survived } \\
\text { in greenhouse }\end{array}$ & $\begin{array}{c}\text { No. of plants having } \\
\text { variations }\end{array}$ & $\begin{array}{c}\text { Variation } \\
\text { rate (\%) }\end{array}$ \\
\hline Potters Purple & 787 & 183 & 114 & 23 & 2.9 \\
Lochinch & 582 & 121 & 74 & 14 & 2.4 \\
Total & 1369 & 304 & 188 & 37 & 2.7 \\
\hline
\end{tabular}




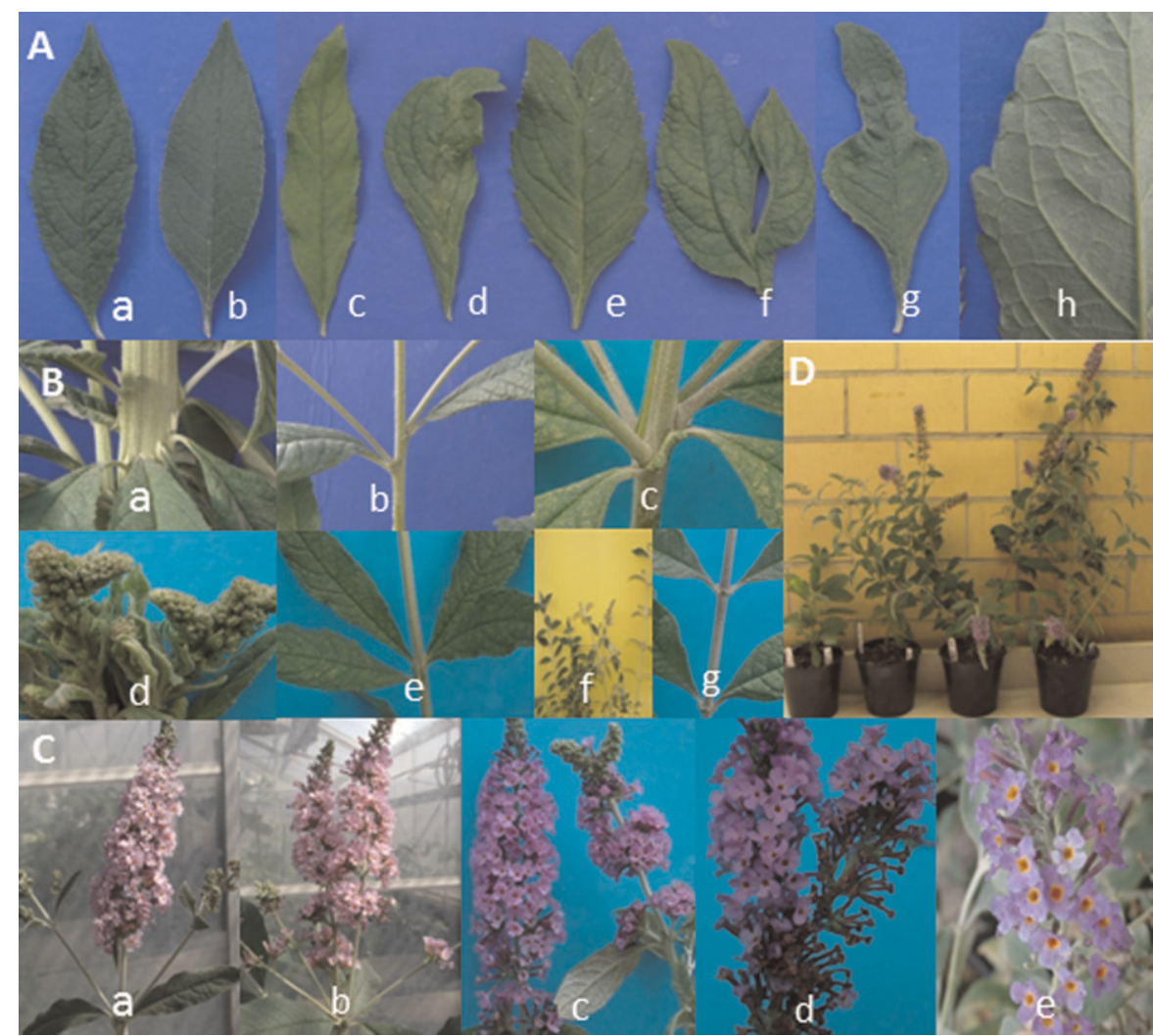

Fig. 2. Morphological variations induced by gamma ray irradiation in Buddleia plants. (A) Variations in leaves. (a-b) Original leaves of 'Potters Purple' and 'Lochinch' on the control plant; (c) narrowed leaf (less than $3 \mathrm{~cm}$ wide); (d-g) deformed leaves; and (h) leaf margin change and leaf hairs disappeared. (B) Variations in stems. (a) flat stem; (b-c) alternate and whorled leaf arrangement; (d) multiple branches; (e) deformed inflorescence on flat stem; and (f) shortened internode; (g) control. (C) Variations in flowers. (a) inflorescence of 'Potters Purple' on the control plant; (b) multiple inflorescences; (c) stem-like structure (flower clusters on each node); (d) split inflorescence; and (e) chimeric flower (a white flower spotted). (D) Variations in plant stature (the far right one is a control).

in the greenhouse. This indicates that the effect of gamma ray irradiation can last a long time (5-6 months) and some damage is permanent, irreversible, and detrimental. In this study, a broad spectrum of variations in leaf, stem, flower, and plant stature were detected in both cultivars. The overall variation rate was closely related to the gamma ray dosage rather than genotypes (cultivars), which is not in agreement with the result from other research where mutation rate varied with cultivars (Lacey and Campbell, 1982; Predieri et al., 1997). For example, in the 50-Gy treatment, the variation rate of 'Potters Purple' and 'Lochinch' were $5.2 \%$ and $5.1 \%$, respectively. When the dosage was raised to $100 \mathrm{~Gy}$, the variation rate for 'Lochinch' doubled to $10.3 \%$ (no data for 'Potters Purple' because very few plants survived the $100-\mathrm{Gy}$ treatment). We noticed that some variations were on the whole plant such as leaf shape and leaf hair, whereas other variations were partial (chimeric) such as flower color and petal number. This suggests that variations occurred in the different layers of cells in the these lines to investigate the genetic or molecular mechanisms behind these variations.

\section{Literature Cited}

Ahloowalia, B.S., M. Maluszynski, and K. Nichterlein. 2004. Global impact of mutation-derived varieties. Euphytica 135:187-204.

Chen, J.J. and R.J. Henny. 2006. Somaclonal variation: An important source for cultivar development for floriculture crops. Floriculture Ornamental and Biotechnology 2:244253.

Dai, W. and C. Castillo. 2007. Factors affecting plant regeneration from leaf tissues of Buddleia species. HortScience 42:1670-1673.

Datta, S.K., D. Chakrabarty, and K.A. Mandal. 2001. Gamma ray-induced genetic manipulation in flower color and shape in Dendranthema grandiflorum and their management through tissue culture. Plant Breed. 120:9192.

Dirr, M.A. 1998. Manual of woody landscape plants. 5th Ed. Stipes Publishing, Champaign, IL.

Hogan, S. 2003. Flora: A gardener's encyclopedia. Timber Press, Inc., Portland, OR

Lacey, C.N.D. and A.I. Campbell. 1982. Progress in mutation breeding of apples (Malus pumila Mill.) at Long Ashton Research Station, Bristol, UK, p. 11-28. In: Induced mutations in vegetatively propagated plants, II. International Atomic Energy Agency, Wein, Austria.

Larkin, P.J. and W.R. Scowcroft. 1981. Somaclonal variation-A novel source of variability from cell culture for plant improvement. Theor. Appl. Genet. 60:197-214.

Li, R., A.H. Bruneau, and R. Qu. 2010. Morphological mutants of St. Augustinegrass induced by gamma ray irradiation. Plant Breed. 129: 412-416.

Maluszynski, M., B.S. Ahloowalia, and B. Sigurbjornsson. 1995. Application of in vivo and in vitro mutation techniques for crop improvement. Euphytica 85:303-315.

Mandal, A.K.A., D. Chakrabarty, and S.K. Datta. 2000. Application of in vitro techniques in mutation breeding of chrysanthemum. Plant Cell Tissue Organ Cult. 60:33-38.

Murashige, T. and F. Skoog. 1962. A revised medium for rapid growth and bioassays with tobacco tissue culture. Physiol. Plant. 15:473497.

Podaras, P. 2005. Breeding a butterfly bush. Landscape Plant News 16:6-7.

Predieri, S. 2001. Mutation induction and tissue culture in improving fruits. Plant Cell. Tiss. Org. Cult. 64:185-210.

Predieri, S., M. Magli, and R.H. Zimmerman. 1997. Pear mutagenesis: In vitro treatment with gamma-rays and field selection for vegetative form traits. Euphytica 93:227-237.

Schum, A. 2003. Mutation breeding in ornamentals: An efficient breeding method? Acta Hort. 612:47-60.

Tobutt, K.R. 1993. Inheritance of white flower color and congested growth habit in certain Buddleia progenies. Euphytica 67:231-235.

Van Harten, A.M. 1998. Mutation breeding: Theory and practical applications. Cambridge Univ. Press, Cambridge, UK. 